\title{
Immunoregulatory gene polymorphisms in women with preeclampsia
}

\author{
Karen PT Pendeloski, Nelson Sass, Maria R Torloni, Rosiane Mattar, Antonio F Moron, Camila S Franchim \\ and Silvia Daher
}

The costimulatory molecules CD28, cytotoxic T-lymphocyte antigen-4 (CTLA-4) (cytotoxic T-lymphocyte-associated antigen-4) and inducible costimulator (ICOS) are believed to have a critical modulatory role in the immune response. However, few studies have been performed on the role of these immune regulatory molecules and their polymorphisms in women with preeclampsia (PE). The aim of our study was to evaluate the CTLA4 (+49 A/G) (rs 231775), CD28 (+17 T/C) (rs 3116496) and ICOS (-1564 T/C) (rs 4675378) gene polymorphisms in Brazilian women with PE. This case-control study included 130 patients with PE and 261 control women without any obstetric or systemic disorders. Genomic DNA was extracted from peripheral blood, and the polymorphism genotyping was performed by digesting the PCR products with the restriction endonucleases $B b v$ l (CTLA-4), Afel (CD28) and Alul (ICOS). Data were analyzed by $\chi^{2}$ or Fisher's exact test; a $P$-value of $<0.05$ was considered as significant. There were significant differences in the ICOS genotype and allelic frequencies between the PE and control groups $(P=0.01$ and $P=0.01$, respectively). We found a significantly lower frequency of the $I C O S(-1564) \mathrm{T}$ allele in women with mild PE compared with the controls. There were no differences in the CTLA-4 (+49 A/G) and CD28 (+17 T/C) genotypes and allelic frequencies between the PE patients and controls. Our data suggest that PE is associated with ICOS, but is not associated with the CTLA-4 or CD28 gene polymorphisms.

Hypertension Research (2011) 34, 384-388; doi:10.1038/hr.2010.247; published online 16 December 2010

Keywords: costimulatory molecules; gene polymorphism; immunotolerance; preeclampsia

\section{INTRODUCTION}

Preeclampsia (PE) affects approximately one in every 10 pregnancies and is an important cause of maternal and perinatal adverse outcomes. In Latin America, hypertensive disorders are the most common cause of maternal death. ${ }^{1}$ Despite its clinical relevance and frequency, the etiology and pathogenic mechanisms of PE remain unclear, possibly because PE is a multi-factorial disease with several different risk factors. Additionally, this condition can present in various clinical forms, ranging from mild $\mathrm{PE}$ occurring late in pregnancy to severe forms that may present early in the second trimester, which, in fact, could have different etiopathogenic pathways. ${ }^{2-5}$

Many investigations suggest that $\mathrm{PE}$ is an immune-mediated disorder. ${ }^{6,7}$ However, there is a paucity of studies that involve immunoregulatory molecules and their polymorphisms in women with PE.

The expression of the cytotoxic T-lymphocyte antigen-4 (CTLA-4) molecule on regulatory $\mathrm{T}$ cells is considered to be critical for the maintenance of tolerance at the maternal-fetal interface. ${ }^{8,9}$ Together with CTLA-4, the costimulatory molecule CD28 and the inducible costimulator (ICOS) gene are important regulators of the immune system, and their corresponding genes are located on the chromosome $2 \mathrm{q} 33 .{ }^{10-12}$
The single-nucleotide polymorphisms of these T-cell regulatory genes have been associated with autoimmune diseases ${ }^{13,14}$ and with acute allograft rejections after liver transplants. ${ }^{15}$ According to current theories, PE can also be considered a type of immune disorder., ${ }^{3,16}$ Until now, only two studies have analyzed the CTLA-4 gene polymorphism in women with PE. The first study involved a small group of Iranian patients ${ }^{17}$ and suggested that heterozygosis could be a predisposing factor for severe PE. However, Jäskeläinen et al. ${ }^{18}$ analyzed the same polymorphism in a Finnish population and reported that the $G$ allele appeared to be the risk allele for PE. To the best of our knowledge, there have been no previous studies assessing the association between PE and the CD28 or ICOS genetic polymorphisms.

Although the exact mechanisms are not yet completely understood, there seems to be a clear genetic predisposition to $\mathrm{PE},{ }^{16,19}$ and chromosome 2 appears to be implicated in this tendency. Coincidentally, the ICOS, CD28 and CTLA-4 genes are located on this chromosome. ${ }^{10,11}$

The aim of our study was to evaluate the CTLA4 (+49 A/G) (rs 231775), CD28 (+17 T/C) (rs 3116496) and ICOS (-1564 T/C) (rs 4675378) gene polymorphisms in Brazilian women with PE. 


\section{METHODS}

\section{Subjects}

This case-control study comprised pregnant women who were referred to the obstetric ward of the Sao Paulo Hospital (Sao Paulo Federal University) or admitted to the Dr Mário de Moraes Altenfelder Municipal Teaching Hospital (both facilities located in Sao Paulo, Brazil) between 2007 and 2009. The study group included 130 women diagnosed with $\mathrm{PE}$ according to the criteria proposed by the 'National High Blood Pressure Education Program'. ${ }^{20}$ According to these recommended guidelines, PE was defined as the presence of systolic blood pressure $\geqslant 140 \mathrm{~mm} \mathrm{Hg}$ and diastolic blood pressure $\geqslant 90 \mathrm{~mm} \mathrm{Hg}$ after 20 weeks of gestation in a previously normotensive woman, accompanied by proteinuria (urinary excretion of $\geqslant 0.3 \mathrm{~g}$ protein in a $24-\mathrm{h}$ specimen). Women with blood pressure $<160 / 110 \mathrm{~mm} \mathrm{Hg}$ (systolic/diastolic), a normal platelet count, normal liver enzyme values and no maternal symptoms were classified as having mild PE; all others were classified as cases of severe PE.

The exclusion criteria consisted of the presence of following: a multiple gestation, fetal death, autoimmune diseases, diabetes, uterine malformation, in vitro fertilization treatment, placental abruption, infection and cancer or any other systemic disease, including pre-existing hypertension.

The control group included 261 pregnant women matched by race to the study group. Control women had to be normotensive during the index pregnancy and must have had a history of at least two previous normal pregnancies without any maternal or fetal disorders.

The study protocol was approved by the Ethics Committees of both aforementioned hospitals, and written informed consent was obtained from all participants.

Upon admission, $10 \mathrm{ml}$ of peripheral blood was collected from each participant in tubes containing ethylenediamine tetraacetic acid (BD Diagnostics, Franklin Lakes, NJ, USA). The tubes were immediately centrifuged to obtain the buffy coat layer containing the polymorphonuclear cells, and the DNA was extracted by the dodecyl trimethyl ammonium bromide/cetyl trimethyl ammonium bromide method. ${ }^{21}$

\section{Genotyping of polymorphisms}

The sequences of the primers and cycling conditions, as well as the genotyping methods have been previously described. ${ }^{12}$ The CTLA-4 (rs231775), CD28 (rs3116496) and ICOS (rs4675378) gene polymorphisms were genotyped by the restriction fragment length polymorphism method. ${ }^{12}$ Briefly, the CTLA-4, CD28 and ICOS PCR products were digested with the BbvI, AfeI and $A l u \mathrm{I}$ restriction endonucleases (New England Biolabs, Beverly, MA, USA), respectively.

The CTLA-4 gene polymorphism genotyping resulted in fragment sizes of $464 \mathrm{bp}(\mathrm{A})$ or 239 and $255 \mathrm{bp}(\mathrm{G})$. The CD28 gene polymorphism resulted in sizes of $149 \mathrm{bp}(\mathrm{C})$ or 125 and $24 \mathrm{bp}(\mathrm{T})$. Finally, the ICOS gene polymorphism genotyping resulted in fragment sizes of $385 \mathrm{bp}(\mathrm{T})$ or 339 and $289 \mathrm{bp}(\mathrm{C})$.

All PCR products were visualized by electrophoresis on an agarose gel that was stained with ethidium bromide.

\section{Statistical analysis}

Two-tailed, pooled Student's $t$-tests were used to analyze continuous variables.

The sample size estimates were based on the CTLA4 $(+49$ A/G) gene polymorphism (rs 231775) frequency, according to the Hap Map Project (http://www.hapmap.org/cgi-perl/gbrowse/hapmap27_B36/) data, which defined an allele risk of $39 \%$ in the European Caucasian population. Applying the allele risk data in the Power and Sample Size Program Version 2.1.30 22 and considering an $80 \%$ power and a two-tailed $\alpha$ value of 0.05 , a sample size of 108 patients per group was determined to be sufficient to detect an association between the alleles and PE.

The Hardy-Weinberg equilibrium tests were performed by calculating the expected frequencies of each genotype and comparing them with the observed values. The single allelic and single genotype frequencies (obtained by direct count) were analyzed by the Fisher's exact or $\chi^{2}$-tests, with the level of significance set at 0.05 and the Bonferroni correction for multiple testing. The odds ratios and 95\% confidence intervals were calculated. A statistical analysis was performed with standard software (SPSS for the Social Science, v13.1 for Windows).
Table 1 Characteristics of women included in the study

\begin{tabular}{lrrr}
\hline Variable & Preeclampsia $\mathrm{n}=130$ & Control $\mathrm{n}=261$ & P-value \\
\hline Age $^{\mathrm{a}}$ & $25.79 \pm 6.85$ & $30.72 \pm 9.29$ & $<0.0001$ \\
Number of pregnancies $^{\mathrm{a}}$ & $1.9 \pm 1.49$ & $2.51 \pm 1.38$ & 0.0003 \\
& & & \\
Race $^{\mathrm{b}}$ & $73(56 \%)$ & $174(67 \%)$ & 0.09 \\
$\quad$ White & $36(28 \%)$ & $60(23 \%)$ & \\
Mulatto & $21(16 \%)$ & $27(10 \%)$ & \\
$\quad$ Black & $33.18 \pm 4.98$ & $31.93 \pm 5.05$ & 0.14 \\
Gestational age at collection & & & \\
\hline
\end{tabular}

aData presented as mean \pm s.e.m. and analyzed by Student's $t$-test.

bata analyzed by $\chi^{2}$-test.

\section{RESULTS}

The clinical characteristics of participants are presented on Table 1.

All single-nucleotide polymorphisms in the PE and control groups were in Hardy-Weinberg equilibrium. The genotype and allele frequencies are shown in Table 2. The genotype and allelic frequencies of the controls and of the patients with mild and severe PE are presented in Table 3.

There were significant differences in ICOS $(-1564 \mathrm{~T} / \mathrm{C})$ genotype (TT vs. TC vs. CC-corrected $P=0.03, \chi^{2}$ test) and allelic frequencies (corrected $P=0.03, \chi^{2}$ test) between PE and controls. We also found a significantly lower frequency of the $\mathrm{T}$ allele in the mild $\mathrm{PE}$ patients compared with the controls (corrected $P=0.03$ ). However, there were no statistically significant differences in the genotype and allelic frequencies between the mild and severe PE groups.

There were no differences in the CTLA-4 (+49 A/G) and CD28 (+49 $\mathrm{A} / \mathrm{G})$ genotypes and allelic frequencies between the PE patients and controls. We detected a significant difference in the CTLA4 +49 genotype frequencies between the mild and severe $\mathrm{PE}$ groups $\left(P=0.03, \chi^{2}\right.$-test $)$, although this was not confirmed after the Bonferroni correction (corrected $P=0.12$ ). Additionally, we did not identify any association between the CTLA-4 and CD28 gene polymorphisms when comparing the controls $v s$. the patients with mild or severe PE.

\section{DISCUSSION}

Our results suggest an association between the ICOS gene polymorphism and PE. However, we did not detect any relationship between the CTLA-4 and CD28 gene polymorphisms and PE.

The genotype frequencies were in Hardy-Weinberg equilibrium in both the patients and controls. Bearing in mind the importance of ethnical matching in disease association studies, our groups were matched by race. ${ }^{23-26}$ In addition, the genotype frequencies were similar to those previously reported for the Brazilian population. ${ }^{12}$

Most association studies between pregnancy and immunoregulatory molecules have focused mainly on CTLA-4. ${ }^{17,18,27}$ The T regulatory (Treg) cells that express the activation marker CTLA- 4 are critical for the maintenance of maternal tolerance to fetal antigens. ${ }^{8,9}$ Additionally, a decreased ratio of CTLA- $4(+) / \mathrm{CD} 28(+)$ expression, both in peripheral blood and in deciduas, seems to be associated with pregnancy loss. ${ }^{28}$ Several studies have shown that ICOS has a pivotal role in T-cell activation and in Th1/Th2 differentiation..$^{29}$ Despite this, the role of ICOS has not been previously investigated in pregnancy, a condition that is clearly influenced by these processes. To the best of our knowledge, this is the first study to simultaneously evaluate these three immunoregulatory molecule gene polymorphisms in pregnancy.

We observed a significantly lower frequency of the ICOS $-1564 \mathrm{~T}$ allele and of the TT genotype in the women with PE compared with 
Table 2 Genotype and allele frequencies of $C T L A-4, C D 28$ and ICOS gene polymorphisms in women with preeclampsia and controls

\begin{tabular}{|c|c|c|c|c|c|}
\hline & Preeclampsia & Control & OR $(95 \% \mathrm{Cl})$ & P-value & Corrected P-value \\
\hline \multicolumn{6}{|l|}{ CTLA-4 (+49) } \\
\hline Genotypes $^{\mathrm{b}}$ & $n=125$ & $n=158$ & & & \\
\hline$A G$ & $47(37.6 \%)$ & $63(39.9 \%)$ & & & \\
\hline $\mathrm{GG}$ & $20(16 \%)$ & $19(12 \%)$ & & & \\
\hline$G G \times(A G+A A)^{c}$ & & & $1.39(0.70-2.74)$ & 0.38 & - \\
\hline$G$ & $87(34.8 \%)$ & $101(32 \%)$ & & & \\
\hline \multicolumn{6}{|l|}{ CD28 (+17) } \\
\hline Genotypes $^{b}$ & $n=125$ & $n=171$ & & & \\
\hline $\mathrm{TT}$ & $84(67.2 \%)$ & $125(73.1 \%)$ & & 0.38 & - \\
\hline $\mathrm{TC}$ & $34(27.2 \%)$ & $41(24 \%)$ & & & \\
\hline C & $48(19.2 \%)$ & 51 (14.9\%) & & & \\
\hline \multicolumn{6}{|l|}{$\operatorname{lcos}(-1564)$} \\
\hline Genotypes $^{\mathrm{b}}$ & $n=124$ & $n=167$ & & & \\
\hline $\mathrm{TT}$ & $52(41.9 \%)$ & $99(59.3 \%)$ & & 0.01 & 0.03 \\
\hline $\mathrm{TC}$ & $60(48.4 \%)$ & $54(32.3 \%)$ & & & \\
\hline $\mathrm{CC}$ & $12(9.7 \%)$ & $14(8.4 \%)$ & & & \\
\hline $\mathrm{TT} \times(\mathrm{TC}+\mathrm{CC})^{\mathrm{c}}$ & & & $0.49(0.30-0.79)$ & 0.004 & 0.012 \\
\hline Alleles $^{c}$ & $n=248$ & $n=334$ & & & \\
\hline$T$ & $164(66.1 \%)$ & 252 (75.4\%) & $0.63(0.44-0.91)$ & 0.01 & 0.03 \\
\hline C & $84(33.9 \%)$ & $82(24.6 \%)$ & & & \\
\hline
\end{tabular}

Abbreviations: $\mathrm{Cl}$, confidence interval; OR, odds ratio.

aBonferroni correction.

b $\chi^{2}$-test.

cFischer's exact test.

the controls. Similar results were reported in patients with type 1 diabetes. ${ }^{30}$ In a study involving Finnish and Estonian participants, Douroudis et al. ${ }^{30}$ detected a marginally significant decrease in frequency of the CTIC154_1 T allele in the group of type 1 diabetics. Thus, this gene polymorphism might be related to the immune/ inflammation processes. Although little is known about the functional role of this polymorphism, other investigators have reported that variations in noncoding regions may influence the mRNA of the ICOS gene and subsequently affect its expression. ${ }^{29,31}$

Jääskeläinen et al. ${ }^{18}$ did not detect an association between the CTLA-4 +49 genotype and PE, but did detect an increased frequency of the $G$ allele in Finnish PE patients. In contrast, an increased frequency of the GA genotype was reported among Iranian women with severe PE. ${ }^{17}$ Our data also showed an increased frequency of the GA genotype in Brazilian women with severe PE; however, this difference was not confirmed after the Bonferroni correction. These controversial findings could be attributed to the sample size, statistical analysis and differences in the polymorphism distribution among races.

The CTLA- 4 expression seems to be critical for the suppressive effects of Treg cells. ${ }^{32}$ Although none of the three studies evaluated the expression of this molecule, differences in this polymorphism seem to modify the CTLA-4 expression and compromise the activity of the Treg cells. ${ }^{8,33,34}$

Further studies are needed to validate the biological significance of the ICOS $(-1564 \mathrm{~T} / \mathrm{C})$ gene polymorphism identified in the present study. Although the number of participants was not large, ours is the first study to investigate the association between PE and this specific genetic marker. These results need to be replicated in larger groups of women and in more ethnically diverse populations.

The genes of the costimulatory molecules CD28, CTLA-4 and ICOS are situated in the same region on chromosome $2 \mathrm{q} 33$. $^{11,12,31}$ As previously reported by other investigators, this chromosome seems to be implicated in a woman's predisposition to PE. ${ }^{10} \mathrm{In}$ addition to being located closely together on the same chromosome, these three molecules seem to be implicated in the Th1-Th2 balance through Treg activation. ${ }^{8,29}$ Previous studies have reported that women with PE have altered Treg cell numbers and/or function. ${ }^{8,35}$ Due to these common characteristics, we can speculate that these three genes could be involved in the susceptibility to the same disease. On the basis of this assumption, we investigated the possible existence of associations between different combinations of these three genetic polymorphisms and PE but detected none (data not shown).

The role of the genes of these costimulatory molecules needs to be further investigated in healthy pregnant women and in those with PE. Specifically, studies assessing the expression of these molecules need to be conducted, including investigations on the relationship between maternal and fetal genotype interactions.

In conclusion, our data suggest an association between PE and the ICOS gene polymorphism, but do not suggest an association between $\mathrm{PE}$ and the CD28 and CTLA-4 gene polymorphisms. 
Table 3 Genotype and allele frequencies of CTLA-4, CD28 and ICOS gene polymorphisms in women with mild and severe PE and controls

\begin{tabular}{|c|c|c|c|c|c|c|}
\hline & Mild PE & Severe $P E$ & Control & OR $(95 \% \mathrm{Cl})$ & P-value & Corrected P-value \\
\hline \multicolumn{7}{|l|}{ CTLA-4 (+49) } \\
\hline Genotypes $^{\mathrm{b}}$ & $n=47$ & $n=76$ & $n=158$ & & & \\
\hline \multirow[t]{3}{*}{$A G$} & 11 (23.4\%) & 34 (44.7\%) & 63 (39.9\%) & & $0.03^{c}$ & $0.09^{c}$ \\
\hline & & & & & $0.05^{d}$ & $0.15^{d}$ \\
\hline & & & & & $0.77^{e}$ & - \\
\hline \multirow{2}{*}{$G G \times(A G+A A)^{f}$} & & & & $2.23(0.97-5.11)^{d}$ & $0.06^{d}$ & - \\
\hline & & & & $0.98(0.42-2.28)^{\mathrm{e}}$ & $1.0^{\mathrm{e}}$ & - \\
\hline Alleles ${ }^{f}$ & $n=94$ & $n=152$ & $n=316$ & & & \\
\hline A & 61 (64.9\%) & $100(65.8 \%)$ & 215 (68\%) & & & \\
\hline \multirow[t]{2}{*}{ G } & $33(35.1)$ & $52(34.2 \%)$ & $101(32 \%)$ & $0.96(0.56-1.65)^{c}$ & $0.89^{c}$ & - \\
\hline & & & & $0.86(0.53-1.41)^{d}$ & $0.62^{d}$ & - \\
\hline TT & 34 (73.9\%) & $50(63.3 \%)$ & $125(73.1 \%)$ & & & \\
\hline \multirow{3}{*}{$\mathrm{TC}$} & 9 (19.6\%) & 25 (31.6\%) & $41(24 \%)$ & & $0.33^{c}$ & - \\
\hline & & & & & $0.45^{d}$ & - \\
\hline & & & & & $0.27^{e}$ & - \\
\hline $\mathrm{CC}$ & $3(6.5 \%)$ & $4(5.1 \%)$ & 5 (2.9\%) & & & \\
\hline \multirow[t]{3}{*}{$\mathrm{TT} \times(\mathrm{TC}+\mathrm{CC})^{f}$} & & & & $1.64(0.73-3.66)^{c}$ & $0.24^{c}$ & - \\
\hline & & & & $1.04(0.49-2.18)^{d}$ & $1.0^{\mathrm{d}}$ & - \\
\hline & & & & $0.63(0.35-1.12)^{\mathrm{e}}$ & $0.14^{\mathrm{e}}$ & - \\
\hline Alleles $^{f}$ & $n=92$ & $n=158$ & $n=342$ & & & \\
\hline $\mathrm{T}$ & 77 (83.7\%) & 125 (79.1\%) & 291 (85.1\%) & & & \\
\hline \multirow[t]{2}{*}{ C } & 15 (16.3\%) & $33(20.9 \%)$ & $51(14.9 \%)$ & $1.35(0.69-2.66)^{c}$ & $0.40^{c}$ & - \\
\hline & & & & $0.89(0.48-1.68)^{d}$ & $0.74^{d}$ & - \\
\hline $\mathrm{CC}$ & $4(8.5 \%)$ & $8(10.4 \%)$ & $14(8.4 \%)$ & & & \\
\hline \multirow[t]{3}{*}{$\mathrm{TT} \times(\mathrm{TC}+\mathrm{CC})^{f}$} & & & & $0.58(0.27-1.24)^{c}$ & $0.19^{c}$ & - \\
\hline & & & & $0.35(0.18-0.69)^{d}$ & $0.002^{\mathrm{d}}$ & $0.006^{d}$ \\
\hline & & & & $0.60(0.35-1.03)^{\mathrm{e}}$ & $0.07^{e}$ & - \\
\hline Alleles $^{f}$ & $n=94$ & $n=154$ & $n=334$ & & & \\
\hline T & 59 (62.8\%) & $105(68.2 \%)$ & 252 (75.4\%) & & & \\
\hline \multirow[t]{3}{*}{ C } & 35 (37.2\%) & $49(31.8 \%)$ & $82(24.6 \%)$ & $0.78(0.45-1.34)^{c}$ & $0.40^{c}$ & - \\
\hline & & & & $0.54(0.33-0.89)^{d}$ & $0.02^{d}$ & $0.06^{d}$ \\
\hline & & & & $0.69(0.45-1.06)^{\mathrm{e}}$ & $0.1^{\mathrm{e}}$ & - \\
\hline
\end{tabular}

Abbreviations: $\mathrm{Cl}$, confidence interval; OR, odds ratio; $\mathrm{PE}$, preeclampsia.

aBonferroni correction.

${ }^{b} \chi^{2}$-test.

The $P$-values were determined between the following: ${ }^{c}$ women with mild preeclampsia and severe preeclampsia; ${ }^{d}$ women with mild preeclampsia and controls; and ${ }^{\mathrm{e}}$ women with severe preeclampsia and controls.

fFischer's exact test.

\section{ACKNOWLEDGEMENTS}

This work was supported by a research grant from Fundação de Amparo a Pesquisa (07/57446-0) and Coordenação de Aperfeiçoamento de Pessoal de Nível Superior, Brazil.

1 Khan KS, Wojdyla D, Say L, Gulmezoglu AM, Van Look PF. WHO analysis of causes of maternal death: a systematic review. Lancet 2006; 367: 1066-1074.
2 Redman CW, Sargent IL. Pre-eclampsia, the placenta and the maternal systemic inflammatory response-a review. Placenta 2003; 24(Suppl A): S21-S27.

3 Sibai B, Dekker G, Kupferminc M. Pre-eclampsia. Lancet 2005; 365: 785-799.

4 Hirashima C, Ohkuchi A, Matsubara S, Suzuki H, Takahashi K, Usui R, Suzuki M. Alteration of serum soluble endoglin levels after the onset of preeclampsia is more pronounced in women with early-onset. Hypertens Res 2008; 31: 1541-1548.

5 Ohkuchi A, Hirashima C, Matsubara S, Suzuki H, Takahashi K, Arai F, Watanabe T, Kario K, Suzuki M. Alterations in placental growth factor levels before and after the onset of preeclampsia are more pronounced in women with early onset severe preeclampsia. Hypertens Res 2007; 30: 151-159. 
6 Allaire AD, Ballenger KA, Wells SR, McMahon MJ, Lessey BA. Placental apoptosis in preeclampsia. Obstet Gynecol 2000; 96: 271-276.

7 Huppertz B. Placental origins of preeclampsia: challenging the current hypothesis. Hypertension 2008; 51: 970-975.

8 Guerin LR, Prins JR, Robertson SA. Regulatory T-cells and immune tolerance in pregnancy: a new target for infertility treatment? Hum Reprod Update 2009; 15 : 517-535.

9 Takahashi T, Tagami T, Yamazaki S, Uede T, Shimizu J, Sakaguchi N, Mak TW, Sakaguchi S. Immunologic self-tolerance maintained by CD25(+) CD4(+) regulatory $\mathrm{T}$ cells constitutively expressing cytotoxic $\mathrm{T}$ lymphocyte-associated antigen 4 . J Exp Med 2000; 192: 303-310.

10 Fitzpatrick E, Goring HH, Liu H, Borg A, Forrest S, Cooper DW, Brennecke SP, Moses EK. Fine mapping and SNP analysis of positional candidates at the preeclampsia susceptibility locus (PREG1) on chromosome 2. Hum Biol 2004; 76: 849-862.

11 Harper K, Balzano C, Rouvier E, Mattei MG, Luciani MF, Golstein P. CTLA-4 and CD28 activated lymphocyte molecules are closely related in both mouse and human as to sequence, message expression, gene structure, and chromosomal location. J Immunol 1991; 147: 1037-1044.

12 Guzman VB, Morgun A, Shulzhenko N, Mine KL, Goncalves-Primo A, Musatti CC, Gerbase-Delima M. Characterization of CD28, CTLA4, and ICOS polymorphisms in three Brazilian ethnic groups. Hum Immunol 2005; 66: 773-776.

13 Kristiansen OP, Larsen ZM, Pociot F. CTLA-4 in autoimmune diseases-a general susceptibility gene to autoimmunity? Genes Immun 2000; 1: 170-184.

14 Cunninghame Graham DS, Wong AK, McHugh NJ, Whittaker JC, Vyse TJ. Evidence for unique association signals in SLE at the CD28-CTLA4-ICOS locus in a family-based study. Hum Mol Genet 2006; 15: 3195-3205.

15 de Reuver P, Pravica V, Hop W, Boor P, Metselaar HJ, Hutchinson IV, Tilanus HW, Kwekkeboom J. Recipient ctla- $4+49$ G/G genotype is associated with reduced incidence of acute rejection after liver transplantation. Am J Transplant 2003; 3: 1587-1594.

16 Roberts CT. Review: Complicated interactions between genes and the environment in placentation, pregnancy outcome and long term health. Placenta 2010; 31(Suppl): S47-S53.

17 Samsami Dehaghani A, Doroudchi M, Kalantari T, Pezeshki AM, Ghaderi A. Heterozygosity in CTLA-4 gene and severe preeclampsia. Int J Gynaecol Obstet 2005; 88: 19-24.

18 Jaaskelainen E, Toivonen S, Keski-Nisula L, Paattiniemi EL, Helisalmi S, Punnonen K, Heinonen S. CTLA-4 polymorphism 49A-G is associated with placental abruption and preeclampsia in Finnish women. Clin Chem Lab Med 2008; 46: 169-173.

19 Chelbi ST, Vaiman D. Genetic and epigenetic factors contribute to the onset of preeclampsia. Mol Cell Endocrinol 2008; 282: 120-129.

20 NHBPEP. Report of the National High Blood Pressure Education Program Working Group on high blood pressure in pregnancy. Am J Obstet Gynecol 2000; 183: S1-S22.
21 Gustincich S, Manfioletti G, Del SG, Schneider C, Carninci P. A fast method for highquality genomic DNA extraction from whole human blood. Biotechniques 1991; 11: 298-300, 302.

22 Dupont WD, Plummer Jr WD. Power and sample size calculations. A review and computer program. Control Clin Trials 1990; 11: 116-128.

23 Bodnar LM, Catov JM, Roberts JM. Racial/ethnic differences in the monthly variation of preeclampsia incidence. Am J Obstet Gynecol 2007; 196: 324-325.

24 Daher S, Sass N, Oliveira LG, Mattar R. Cytokine genotyping in preeclampsia. Am J Reprod Immunol 2006; 55: 130-135.

25 Pena SDJ, Carvalho-Silva DR, Alves Silva J, Prado VF, Santos FR. Retrato Molecular do Brasil. Ciência Hoje 2000; 159: 16-25.

26 Santos RV, Maio MC. Qual 'Retrato do Brasil'? Raça, Biologia, identidades e política na era da genômica. Mana 2004; 10: 61-95.

27 Tsai AF, Kaufman KA, Walker MA, Karrison TG, Odem RR, Barnes RB, Scott JR, Schreiber JR, Stephenson MD, Ober C. Transmission disequilibrium of maternallyinherited CTLA-4 microsatellite alleles in idiopathic recurrent miscarriage. J Reprod Immunol 1998; 40: 147-157.

28 Wang X, Ma Z, Hong Y, Lu P, Lin Q. Expression of CD28 and cytotoxic T lymphocyte antigen 4 at the maternal-fetal interface in women with unexplained pregnancy loss. Int J Gynaecol Obstet 2006; 93: 123-129.

29 Shilling RA, Pinto JM, Decker DC, Schneider DH, Bandukwala HS, Schneider JR, Camoretti-Mercado B, Ober C, Sperling Al. Cutting edge: polymorphisms in the ICOS promoter region are associated with allergic sensitization and Th2 cytokine production. $\mathrm{J}$ Immunol 2005; 175: 2061-2065.

30 Douroudis K, Laine AP, Heinonen M, Hermann R, Lipponen K, Veijola R, Simell O, Knip M, Uibo R, Ilonen J, Kisand K. Association of CTLA4 but not ICOS polymorphisms with type 1 diabetes in two populations with different disease rates. Hum Immunol 2009; 70: 536-539.

31 Kaartinen T, Lappalainen J, Haimila K, Autero M, Partanen J. Genetic variation in ICOS regulates mRNA levels of ICOS and splicing isoforms of CTLA4. Mol Immunol 2007; 44: 1644-1651.

32 Flores-Borja F, Jury EC, Mauri C, Ehrenstein MR. Defects in CTLA-4 are associated with abnormal regulatory T cell function in rheumatoid arthritis. Proc Natl Acad Sci USA 2008; 105: 19396-19401.

33 Kouki T, Sawai Y, Gardine CA, Fisfalen ME, Alegre ML, DeGroot LJ. CTLA-4 gene polymorphism at position 49 in exon 1 reduces the inhibitory function of CTLA-4 and contributes to the pathogenesis of Graves' disease. J Immunol 2000; 165: 6606-6611.

34 Maurer M, Loserth S, Kolb-Maurer A, Ponath A, Wiese S, Kruse N, Rieckmann P. A polymorphism in the human cytotoxic T-lymphocyte antigen 4 (CTLA4) gene (exon $1+49$ ) alters T-cell activation. Immunogenetics 2002; 54: 1-8.

35 Saito S, Nakashima A, Shima T, Ito M. Th1/Th2/Th17 and regulatory T-cell paradigm in pregnancy. Am J Reprod Immunol 2010; 63: 601-610. 